\title{
Ungrading: why rating students undermines learning (and what to do instead)
}

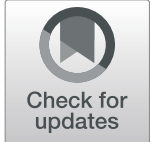

Beatriz Moya(1)

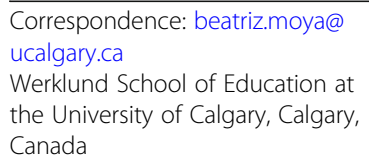

Correspondence: beatriz.moya@ ucalgary.ca

Werklund School of Education at the University of Calgary, Calgary, Canada

\section{Book details}

Blum, S. (2020). Ungrading: Why rating students undermines learning (and what to do instead). West Virginia University Press.

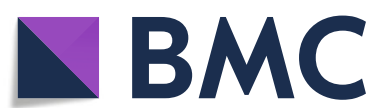

(c) The Author(s) 2021 Open Access This article is licensed under a Creative Commons Attribution 4.0 International License, which permits use, sharing, adaptation, distribution and reproduction in any medium or format, as long as you give appropriate credit to the original author(s) and the source, provide a link to the Creative Commons licence, and indicate if changes were made. The images or other third party material in this article are included in the article's Creative Commons licence, unless indicated otherwise in a credit line to the material. If material is not included in the article's Creative Commons licence and your intended use is not permitted by statutory regulation or exceeds the permitted use, you will need to obtain permission directly from the copyright holder. To view a copy of this licence, visit http://creativecommons.org/licenses/by/4.0/. The Creative Commons Public Domain Dedication waiver (http://creativecommons.org/publicdomain/zero/1.0/) applies to the data made available in this article, unless otherwise stated in a credit line to the data. edited by Dr. Susan D. Blum provides a greater understanding of why there is a growing number of educators considering that grades should be eliminated from the educational system. This assessment for learning book is significantly helpful as it provides theoretical and practical groundings for educators who are troubled by the current grading system. Throughout this book, ungrading conceptualizations, applications and reflections are threaded into 13 diverse yet commensurable course experiences of novice and experienced practitioners who teach humanities, social sciences and STEM at schools, universities, and colleges in North America. Ungrading is a close, collegial, and engaging book that brings a deep reflection into our assessment models, practices, and experiences. Most importantly, it incentivizes us to visualize a 'what if' scenario, acknowledging the tensions and challenges experienced by instructors who have reduced or eliminated grades almost ubiquitous presence in the educational system.

The foreword of Ungrading was written by Kohn (2020), who provides strong foundations and logical arguments that help newcomers - even skeptics - understand ungrading. Kohn (2020) also offers a clear and succinct starting point to the book's chapters when explaining that "(a) grades have been driving much of what happens in their classrooms, (b) this is a serious problem, and (c) it doesn't have to be that way" (p. xix).

The book is logically sequenced in three parts: foundations and models, practices, and reflections. The first part, foundations and models, is written in five chapters with the contributions of Jesse Stommel, Aaron Blackwelder, Susan D. Blum, Starr Sackstein, and Arthur Chiaravalli. This part presents ungrading at a theoretical level connected to real-life teaching settings, addressing main models, concepts, reasons, problems, and methods; I see this part primarily oriented to ungrading explorers. The 
second part, practices, provides five detailed ungrading course implementation experiences written by Laura Gibbs, Christina Katopodis, Cathy N. Davidson, Christopher Riesbeck, Clarissa Sorensen-Unruh, and Gary Chu. From my perspective, this part aims to ungrading potential users. The last part, reflections, approaches three cases developed by Marcus Schultz-Bergin, Joy Kirr and John Warner, which in my understanding, emphasize the practitioners' analytical perspective to reach novice ungrading implementers.

From a general perspective, this book maintains a critical perspective on the culture, which sustains grading. For instance, it unveils inherent problems with the current grading system, such as the lack of consistency with grade inflation or deflation and their communication limitations by reducing students' differences to letters or numbers. This incentivized me to explore grading as a tangled and idiosyncratic concept compounded by qualities that are not always reflective of students' learning. As readers move along, the authors draw from their experiences and research to expand on how grades promote academic performance - rather than learning. These implications are strongly connected to academic integrity since a culture that promotes extreme attention to achievement could push some students to cut corners and compromise their process. Likewise, the authors argue how grades have been used as a tool for segregation and show how grades can also become a control form, incentivizing students' work to meet requirements instead of expanding their knowledge, practice, or values from intrinsic motivation. These reasonings and examples are used to challenge grades' presence in the educational system. The positionality against grades in this book is clear, so it depends on the readers' experiences and frameworks on how this dialectic unfolds.

In the narratives, it is also palpable that grades are currently an integral element of the system. Hence, I valued how this book openly reveals different educators' struggles while adapting their practices to meet institutional expectations and ungrading principles. For instance, the authors explain alternative approaches, including pass/fail systems, students' assigning grades and grade abolition. The chapter contributors also elaborate on how ungrading allowed changes in their curriculum, pedagogy, and reflective practice. At a micro level, the authors share real-life cases with implementations of process letters, grade-free zones, minimal grading, contract grading, individual plans, and portfolio conferences. In my perspective, these narratives evoke teachers' lounge conversations or faculty learning communities' meetings with possibilities for agreeing and contradicting views among authors and readers.

Changing cultures can be a slow-motion process; therefore, I appreciated the developmental angle of this book's experiences as ungrading practices were shaped by different contextual framings, diverse teachers and faculties' levels of expertise and varying levels of students' acceptance and engagement. Ungrading might be a radical concept by itself, but I recognize that one underlying message is that its inclusion does not emerge from imposition; it is quite the opposite. It requires constant collaboration, negotiation, and consensus among main stakeholders. It involves processes that are interwoven into a particular setting. Ungrading is not intended as a finish line or as a recipe to be replicated. It represents a bottom-up transformation that must be acted upon, monitored, and analyzed to benefit students' learning. 
The intended audience of Ungrading is as diverse as its contributors. I found its straightforward language explains complex concepts and processes with constant connections to real-life teaching; I assume that this choice allows resonance at different levels as I could imagine myself reading this book using different hats I have worn, as a student teacher, as a schoolteacher, as a college teacher and as a faculty developer.

After reading this book, I recognize an interest in learning more about adaptations beyond classroom experiences and course implementation. To me, it was hard to imagine how ungrading could escalate to higher institutional levels as the overall educational system relies on grades, and accountability is increasing its presence worldwide. The current wave of scientific managerialism relies on quantitative measures, for instance, in students' enrollment and funding allocation. Regarding the latter, the access to resources for many institutions is tightly attached to meeting graduation and approval rates, and the formulas used to calculate those rates are based on students' grades. Therefore, I wonder how ungrading practices could reframe admission processes. I also wonder how funding agencies would approach ungraded programs. Answers to these questions are certainly outside the scope of this book, yet some connections could unavoidably emerge for immersed readers.

There are many reasons to regard this compilation as a valuable resource: it provides clear arguments for ungrading while expanding on definitions, models, and implications approached by different voices. It intentionally promotes an inclusive learning orientation in the classroom and invites eluding arbitrary and unreflective assessment. The ideas shared throughout this book are intellectually seductive, especially for educators who see grading as the one change they would like to make in the educational system. Overall, I close by agreeing with Blum (2020) that Ungrading is "a contribution toward the structural change that will make schools about rewarding students with learning" (p. 227).

Author's contributions

$100 \%$. The author read and approved the final manuscript.

Authors' information

Beatriz Moya is a Ph.D. student in the Werklund School of Education at the University of Calgary.

Funding

Chilean National Agency of Investigation and Development (ANID in Spanish) and University of Calgary.

Availability of data and materials

N/A.

\section{Declarations}

Competing interests

Ph.D. student working with Dr. Sarah Elaine Eaton.

Published online: 03 May 2021

References

Blum S (2020) Ungrading: why rating students undermines learning (and what to do instead). West Virginia University Press, Morganstown.

Kohn, A. (2020). Foreword. In S. Blum (Ed.), Why rating students undermines learning (and what to do instead). West Virginia University Press:xiii-xx, 41, Supplement 1, DOI: https://doi.org/10.1027/0227-5910/a000663

\section{Publisher's Note}

Springer Nature remains neutral with regard to jurisdictional claims in published maps and institutional affiliations. 